\title{
Erratum to: Seasonal discharge and chemical flux variations of rivers flowing into the Bayhead canal of Durban Harbour, South Africa
}

\author{
Kavandren Moodley $^{1} \cdot$ Srinivasan Pillay $^{1} \cdot$ Keshia Pather $^{1} \cdot$ Hari Ballabh $^{1}$
}

Published online: 24 August 2016

(C) Science Press, Institute of Geochemistry, CAS and Springer-Verlag Berlin Heidelberg 2016

\section{Erratum to: Acta Geochim \\ DOI 10.1007/s11631-016-0100-z}

In the original publication the authors have erroneously omitted to reference the Figs. 4 and 6. The correct figure caption and the reference are provided in this erratum.

Fig. 4 Interpolated images of Bayhead Canal chemical data-blue indicates low values transitioning to red indicating high values. $\mathrm{Cr}, \mathrm{Hg}$ and $\mathrm{Ni}$ were undetected in the wet season (Moodley et al. 2015)
Fig. 6 Evidence of illegal dumping at upstream site 1 (uMbilo River) (Moodley et al. 2015)

\section{Reference}

Moodley K, Pillay S, Pather K (2015) Spatiotemporal characterization of water chemistry and pollution sources of the Umhlatuzana, Umbilo and Amanzimnyama River catchments of Durban, KwaZulu-Natal, South Africa. Environ Earth Sci 74:1273. doi:10.1007/s12665-015-4118-z

The online version of the original article can be found under doi:10.1007/s11631-016-0100-z.

Hari Ballabh

ballabh2228@gmail.com

1 School of Agricultural, Earth and Environmental Sciences,

University of KwaZulu-Natal, Westville Campus,

Durban 4000, South Africa 